\title{
Doenças da vinagreira no Estado do Maranhão
}

\author{
Gilson Soares da Silva, Adriano Soares Rêgo, Raycenne Rosa Leite
}

Departamento de Fitotecnia e Fitossanidade, Universidade Estadual do Maranhão, CEP 65001-970, São Luís,MA.

Autor para correspondência: Gilson Soares da Silva (gilson_soares@uol.com.br)

Data de chegada: 22/05/2014. Aceito para publicação em: 27/10/2014.

$10.1590 / 0100-5405 / 2002$

\section{RESUMO}

Silva, G. S., Rêgo, A. S., Leite, R.R. Doenças da vinagreira no Estado do Maranhão. Summa Phytopathologica, v.40, n.4, p.378-380, 2014.

Neste trabalho, são descritas as principais doenças da vinagreira (Hibiscus sabdariffa) que ocorrem no Estado do Maranhão. Os patógenos identificados foram Cercospora malayensis, Corynespora cassiicola, Lasiodiplodia theobromae, Meloidogyne incognita, Phytophthora nicotianae e Sclerotium rolfsii.

Palavras-chave adicionais: vinagreira, levantamento, patógenos.

\section{ABSTRACT}

Silva, G. S. , Rêgo, A. S., Leite, R.R. Diseases of roselle in the state of Maranhão, Brazil. Summa Phytopathologica, v.40, n.4, p.378-380, 2014.

In this paper, the most common diseases affecting roselle (Hibiscus sabdariffa) in the state of Maranhão, Brazil, are described. The identified pathogens were
Cercospora malayensis, Corynespora cassiicola, Lasiodiplodia theobromae, Meloidogyne incognita and Sclerotium rolfsdii.

Additional keywords: roselle, survey, pathogens.

A vinagreira (Hibiscus sabdariffa L.), também conhecida como rosele, rosela e azedinha é uma malvácea de origem africana, possivelmente introduzida no Brasil pelos escravos. No Maranhão, a vinagreira destaca-se como uma das hortaliças mais consumidas pela população, sendo utilizada no preparo de pratos típicos (7). Suas folhas são ricas em vitaminas A e B, sais minerais e aminoácidos (6). $\mathrm{Na}$ medicina popular é utilizada como diurética, calmante e antiescorbútico. A vinagreira tem, ainda, um enorme potencial como fonte de corante para a indústria alimentícia (4) além de produtora de fibras para a fabricação de aniagem.

Informações sobre doenças que incidem sobre essa planta são escassas na literatura nacional. Silva (9) relatou a ocorrência de Meloidogyne incognita raça 3 em plantios estabelecidos na Ilha de São Luís. Posteriormente, morte de plantas foram registradas em diversas localidades, causadas por Phytophthora parasitica causando a podridão de raízes e do colo (9). No Pará, Poltronieri et al.(8) relataram a ocorrência de Corynespora cassiicola e Costa et al. (5) descreveram uma outra doença foliar causada por Cylindrocladium sp. No exterior, há relatos de doenças importantes da vinagreira causadas por Phytophthora e Fusarium, especialmente na África e América Central $(1,2,3)$.

Considerando-se a importância econômica e social da vinagreira e a carência de informações sobre os problemas fitossanitários da cultura, realizou-se um levantamento para se identificar as doenças que incidem sobre a vinagreira no Maranhão. Amostras de plantas com sintomas foram coletadas em diversos pólos produtores na Ilha de São Luís, acondicionadas em sacos plásticos e transportadas em isopor até o Laboratório de Fitopatologia na Universidade Estadual do Maranhão, em São Luís, para os isolamentos e identificação dos patógenos. Os fungos foram isolados pelos métodos rotineiramente utilizados, em meio de BDA, em placas de Petri e posteriormente repicados para tubos de ensaio com os meios BDA ou V-8 ágar. Inoculações em plantas sadias foram realizadas com todos os fungos, pulverizando-se suspensões de conídios sobre a parte aérea ou depositando-se discos de cultura sobre o colo das plantas. No caso específico da cercosporiose, dada as dificuldades em se obter grande número de conídios do fungo, a inoculação foi realizada depositando-se discos de cultura sobre a face abaxial das folhas. Após a inoculação, as plantas foram mantidas em câmara úmida por $48 \mathrm{~h}$ e em seguida transferidas para casa de vegetação até o aparecimento dos sintomas. Em todos os casos, o reisolamento dos patógenos confirmou os Postulados de Koch.

Foram identificadas várias doenças tais como podridão das raízes e do caule, manchas foliares, seca dos ramos, murcha de esclerócio e as galhas das raízes.

A cercosporiose (Cercospora malayensis Stevens \& Solheim) foi encontrada em todas as áreas amostradas. Ataca a parte aérea das plantas, causando lesões necróticas, de coloração marrom-avermelhada, medindo 0,2 a $0,5 \mathrm{~cm}$ de diâmetro, pardo-avermelhadas, com bordos escuros (Fig.1A). A importância dessa doença se intensifica na época chuvosa, mais propícia ao desenvolvimento do patógeno. Como as folhas são o principal produto comercializado, a doença é responsável por elevadas perdas, uma vez que folhas com manchas não são aceitas pelo mercado.

A mancha de corinéspora (Corynespora cassiicola (Berk. \& Curtis) Wei é uma doença de ocorrência esporádica. Os sintomas se caracterizam por lesões foliares arredondadas, de coloração marrom, halo estreito, de coloração amarela, medindo até $1 \mathrm{~cm}$ de diâmetro (Fig.1B). Quando várias lesões surgem no limbo foliar, as folhas amarelecem e tendem a cair, comprometendo a comercialização do 

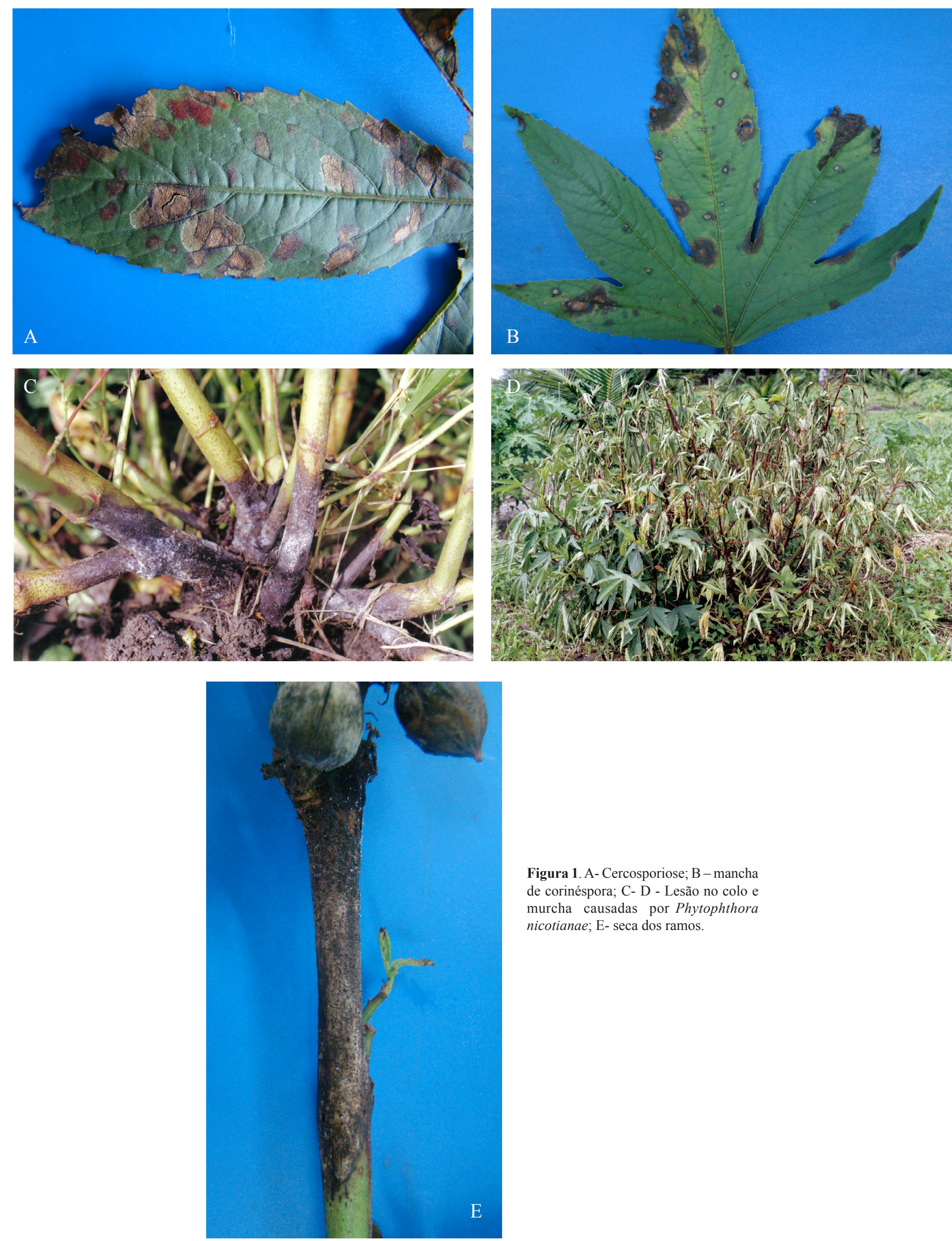

Figura 1. A- Cercosporiose; B - mancha de corinéspora; C- D - Lesão no colo e murcha causadas por Phytophthora nicotianae; E- seca dos ramos. 
produto.

A Podridão do colo e das raízes [Phytopthora nicotianae Breda de Haan (Phytophthora parasitica Dastur)] é a mais destrutiva doença da vinagreira, causando em algumas áreas elevadas perdas. E s t a doença ocorre com mais freqüência na época chuvosa ou em plantios com excesso de irrigação. Plantas atacadas exibem sintomas de murcha e amarelecimento da parte aérea (Fig. 1D). No colo, surge um crescimento branco constituído pelas estruturas do patógeno, micélio e esporângios, que progride para a parte superior do caule deixando os tecidos com coloração amarronzada (Fig. 1C). Com a evolução da doença as plantas perdem completamente as folhas, secam e morrem.

A seca dos ponteiros (Lasiodiplodia theobromae (Pat.) Griffon \& Maubl.) foi constatada em apenas duas propriedades, não se constituindo, no momento, um problema muito sério. Os sintomas característicos surgem em plantas adultas, na forma de seca descendente dos ramos (Fig. 1E). As partes atacadas tomam a coloração cinza, sobre a qual surgem numerosos picnídios negros, ostiolados. Em ataques severos, a doença pode atingir grandes porções dos ramos, comprometendo a produção de folhas.

A murcha de esclerócio (Sclerotium rolfsii Sacc) causa perdas em plantios com excesso de matéria orgânica. A doença se caracteriza como murcha e amarelecimento da parte aérea das plantas, podendo levá-las à morte. Os sinais do patógeno surgem na base do caule, na forma de inúmeros escleródios, inicialmente de cor branca e posteriormente de coloração marrom. Ocorre em algumas áreas, especialmente naquelas onde se cultivam outros hospedeiros suscetíveis como o feijão caupi (Vigna unguiculata (L.) Walp.

As galhas das raízes (Meloidogyne incognita (Kofoid \& White) Chitwood Raça 3) é uma doença relativamente freqüente em plantio de vinagreira. Foi identificada em 1994 (9), na Ilha de São Luís, causando danos leves. Os sintomas são deficiência mineral acentuada na parte aérea, murcha de plantas nas horas mais quentes do dia e redução no crescimento. Os sintomas mais conspícuos são galhas nas raízes, resultado da hiperplasia e hipertrofia de células e tecidos, alterados pela ação parasitária do nematoide.

Mais pesquisas, visando desenvolver formas de manejo das doenças que incidem sobre a vinagreira são necessárias, especialmente nos dias atuais quando a vinagreira começa a despertar grande interesse da indústria farmacêutica como fonte de medicamentos e antioxidantes.

\section{REFERÊNCIAS BIBLIOGRÁFICAS}

1. Agbenin, O. N. ; M. O. Ogunlana Occurence of Fusarium wilt and nematodes on red calyx roselle ( Hibiscus sabdariffa) in northern Nigeria. Journal of Plant Protection Research, Poznain, v. 46, n. 2, p. 117-122. 2005.

2. Alconero, R.; E. Stone Phytophthora nicotianae in roselle and kenaf in Puerto Rico. Plant Disease Reporter, Washington, v.53, n. 9, p.702-705. 1969.

3. Amusa, N. A. ; A. A. Adegbite ; M. O., Oladapo Vascular wilt of roselle ( Hibiscus sabdariffa L. var. sabdariffa) in the humid Forest region of South-western Nigeria. Journal of Plant Pathology, Bari, v.4, n. 2, p. 122-125. 2005.

4. Bittencourt, A.M.; I.S.S. Guimarães, I. S. S. Vinagreira - fonte de antocianinas para alimentos. Rio de Janeiro, Embrapa/CTAA, 3 p. (Comunif cado Técnico,18), 1985.

5. Costa, R. C.; Poltronieri, L. S.; França, S. K. S.; Nascimento, M. M.; V. S. Miranda, V. S.; Poltronieri, T. P. S.; Xavier, J. R. M.; Reis, D. C. S. Cylindrocladium sp. causando lesões foliares em vinagreira no Estado do Pará. Tropical Plant Pathology, Lavras, v.33, suplemento, p.231, 2008.

6. Khatounian, C. A. Produção de alimentos para consumo doméstico no Paraná. Londrina: IAPAR, 1994.193 p.

7. Luz, F. J. F.; Sá Sobrinho, A. F. Vinagreira (Hibiscus sabdariffa).In: CARDOSO, M. O. (Coord.) Hortaliças não-convencionais da Amazônia. Brasília:Embrapa - SPI: Manaus:Embrapa CPAA, 1997. p. 63-69.

8. Poltronieri, T. P. S.; L. S. Poltronieri, L. S.; Verzignassi, J. R.; Benchimol, R. L.; Carvalho, E. A.Vinagreira: novo hospedeiro de Corynespora cassiicola no Pará. Summa Phytopathologica, Botucatu,v.38, n.2, p.167, 2012.

9. Silva, G. S. Vinagreira, novo hospedeiro de Meloidogyne incognita raça 3. Nematologia Brasileira, Piracicaba, v.18, n.1/2, p.106-107, 1994.

10. Silva, G. S. Phytophthora nicotianae, um novo patógeno da vinagreira (Hibiscus sabdariffa) no Brasil. Fitopatologia brasileira, Brasília, v.26, suplemento, p. 320. 2001. 